\title{
Rudaea cellulosilytica gen. nov., sp. nov., isolated from soil
}

\author{
Hang-Yeon Weon, ${ }^{1}$ Seung-Hee Yoo, ${ }^{2}$ Yoo-Jeong Kim, ${ }^{2}$ Chang-Muk Lee, ${ }^{2}$ \\ Byung-Yong Kim, ${ }^{2}$ Young-Ah Jeon, ${ }^{2}$ Seung-Beom Hong, ${ }^{2}$ \\ Rangasamy Anandham ${ }^{3}$ and Soon-Wo Kwon ${ }^{2}$
}

Correspondence

Soon-Wo Kwon

swkwon@rda.go.kr

\author{
${ }^{1}$ Mushroom Research Division, National Institute of Horticultural and Medicinal Crop, Rural \\ Development Administration (RDA), Suwon 441-707, Republic of Korea \\ ${ }^{2}$ Korean Agricultural Culture Collection (KACC), National Agrobiodiversity Center, RDA, Suwon \\ 441-707, Republic of Korea \\ ${ }^{3}$ Organic Agriculture Division, National Academy of Agricultural Science, RDA, Suwon 441-707, \\ Republic of Korea
}

\begin{abstract}
A yellow-pigmented, Gram-negative, aerobic, rod-shaped bacterium, strain $\mathrm{KIS} 3-4^{\top}$, was isolated from soil collected on Daechung Island in the West Sea of Korea. Phylogenetic analysis based on the $16 \mathrm{~S}$ rRNA gene sequence placed strain KIS3 $-4^{\top}$ in a distinct lineage in the family Xanthomonadaceae. Strain KIS3 $-4^{\top}$ shared $87.3-93.7 \%$ sequence similarity with members of the family Xanthomonadaceae, and was related most closely to the genera Dyella and Dokdonella. In its biochemical characteristics, strain KIS3 $-4^{\top}$ was clearly separable from other genera within the family Xanthomonadaceae on the basis of the hydrolysis of cellulose and urea, high $\mathrm{G}+\mathrm{C}$ content $(64 \mathrm{~mol} \%)$ and fatty acid profile. Major fatty acids ( $>10 \%$ of the total fatty acids) were iso- $\mathrm{C}_{17: 1} \omega 9 c(32.8 \%)$, iso- $\mathrm{C}_{17: 0}(18.0 \%)$ and iso- $\mathrm{C}_{16: 0}(12.7 \%)$. Q-8 was the predominant respiratory quinone. Phosphatidylethanolamine and several unidentified aminophospholipids and phospholipids were present. Based on its unique phenotypic, genotypic and phylogenetic features, strain KIS3 $-4^{\top}$ represents a novel genus and species, for which the name Rudaea cellulosilytica gen. nov., sp. nov. is proposed. The type strain of Rudaea cellulosilytica is KIS3- $4^{\top}\left(=\operatorname{KACC} 12734^{\top}=\mathrm{JCM} 15422^{\top}\right)$.
\end{abstract}

The family Xanthomonadaceae consists of Gram-negative, rod-shaped bacteria. Its members are characterized by positive catalase activity, negative nitrate reduction (with the exception of Stenotrophomonas) and variable oxidase activity. Chemotaxonomically, they have complex fatty acid profiles that include branched-chain and/or hydroxyl fatty acids, and contain ubiquinone Q-8 as the predominant isoprenoid quinone. According to Saddler \& Bradbury (2005), the members of the family Xanthomonadaceae were Xanthomonas, Frateuria, Fulvimonas, Luteimonas, Lysobacter, Nevskia, Pseudoxanthomonas, Rhodanobacter, Schineria, Stenotrophomonas, Thermomonas and Xylella. Since then, the genera Aquimonas (Saha et al., 2005), Aspromonas (Jin et al., 2007), Dokdonella (Yoon et al., 2006), Dyella (Xie \& Yokota, 2005), Luteibacter

The GenBank/EMBL/DDBJ accession number for the 16S rRNA gene sequence of strain KIS3-4 $4^{\top}$ is EU741687.

Images of cells of strain KIS3-4 ${ }^{\top}$ and fatty acid composition by 2-D TLC and a table of fatty acid comparisons are available as supplementary material with the online version of this paper.
(Johansen et al., 2005) and Silanimonas (Lee et al., 2005) have been added to the family.

A soil sample was collected from Daechung Island in the West Sea, Republic of Korea. Soil $(1 \mathrm{~g})$ was suspended in $9 \mathrm{ml}$ of $0.85 \% \mathrm{NaCl}(\mathrm{w} / \mathrm{v})$ and serially diluted solutions were plated on R2A agar (Reasoner \& Geldreich, 1985). A strain, designated KIS3 $-4^{\mathrm{T}}$, was isolated after incubation at $30{ }^{\circ} \mathrm{C}$ for 4 days.

Phenotypic characteristics, including Gram-staining, catalase and oxidase activity and hydrolysis of CM-cellulose, casein, chitin, DNA, hypoxanthine, tyrosine, Tween 80, starch and xanthine, were determined using the methods of Smibert \& Krieg (1994). The $\mathrm{pH}$ range ( $\mathrm{pH} 4-10$ at intervals of $1 \mathrm{pH}$ unit) for growth was determined on R2A agar that was buffered with citrate/phosphate buffer or Tris/HCl (Breznak \& Costilow, 1994). Growth with 1, 2, 3 and $5 \% \mathrm{NaCl}(\mathrm{w} / \mathrm{v})$, and at various temperatures $\left(5-50{ }^{\circ} \mathrm{C}\right.$ at intervals of $5{ }^{\circ} \mathrm{C}$ ) was investigated in $\mathrm{R} 2 \mathrm{~A}$ broth. Tests with the API 20NE, API 20E, API ID 32GN and API ZYM systems (bioMérieux) were generally performed according to the manufacturer's instructions. The API ZYM test strip 
was read after $4 \mathrm{~h}$ incubation at $30{ }^{\circ} \mathrm{C}$, whilst the other API strips were examined after 7 days at $30{ }^{\circ} \mathrm{C}$. Cell morphology was observed by transmission electron microscopy (912AB; LEO) and phase-contrast microscopy (Axio Imager.A1; Zeiss) by using cells grown on R2A agar.

Polar lipids were analysed according to Minnikin et al. (1984). Fatty acid methyl esters were extracted and prepared by using the standard protocol of the Microbial Identification System (MIDI) after cells were grown on $\mathrm{R} 2 \mathrm{~A}$ agar for 2 days at $30{ }^{\circ} \mathrm{C}$. Isoprenoid quinones were analysed by HPLC as described by Groth et al. (1996). The DNA G $+\mathrm{C}$ content was determined by HPLC analysis of deoxyribonucleosides as described by Mesbah et al. (1989) using a reversed-phase column (Supelcosil LC-18-S; Supelco).

The 16S rRNA gene sequence was determined by PCR amplification (Kwon et al., 2003) and direct sequencing (Hiraishi, 1992). A partial 16S rRNA gene sequence (1384 nt) was determined for strain KIS3-4 ${ }^{\mathrm{T}}$. CLUSTAL $\mathrm{W}$ version 1.8 (Thompson et al., 1994) was used to align the sequence of strain $\mathrm{KIS} 3-4^{\mathrm{T}}$ with corresponding sequences from related taxa retrieved from public databases. Phylogenetic analysis was performed using MEGA version 3.1 (Kumar et al., 2004) with the neighbour-joining and maximumparsimony methods. Bootstrap values were calculated from 1000 replications.

Strain KIS3 $-4^{\mathrm{T}}$ grew on R2A agar but not on nutrient agar, trypticase soy agar or MacConkey agar (all from Difco). Cells of strain KIS3-4 ${ }^{\mathrm{T}}$ were aerobic, Gram-negative, motile with peritrichous flagella, rod-shaped $(0.5 \mu \mathrm{m}$ wide and $1.0-3.0 \mu \mathrm{m}$ long) (see Supplementary Fig. S1, available in IJSEM Online). The phenotypic characteristics that differentiate strain $\mathrm{KIS} 3-4^{\mathrm{T}}$ from related genera are listed in Table 1.

Polar lipids of strain KIS3-4 $4^{\mathrm{T}}$ included phosphatidylethanolamine and several unidentified aminophospholipids

Table 1. Characteristics of strain $\mathrm{KIS} 3-4^{\top}$ and related members of the family Xanthomonadaceae

Taxa: 1, Rudaea cellulosilytica gen. nov., sp. nov. KIS3-4 ${ }^{\mathrm{T}}$; 2, Aquimonas (data from Saha et al., 2005); 3, Dokdonella (Cunha et al., 2006; Yoon et al., 2006); 4, Dyella (An et al., 2005; Kim et al., 2006; Xie \& Yokota, 2005); 5, Frateuria (An et al., 2005; Kim et al., 2006; Saddler \& Bradbury, 2005; Yoon et al., 2006); 6, Fulvimonas (Mergaert et al., 2002; Yoon et al., 2006); 7, Luteibacter (Johansen et al., 2005); 8, Rhodanobacter (De Clercq et al., 2006; Im et al., 2004; Lee et al., 2007; Nalin et al., 1999; Weon et al., 2007). +, Positive; w, weak; v, variable among species or strains; -, negative; ND, no data available; i-, iso-branched. Data in parentheses are for the type strain of the type species.

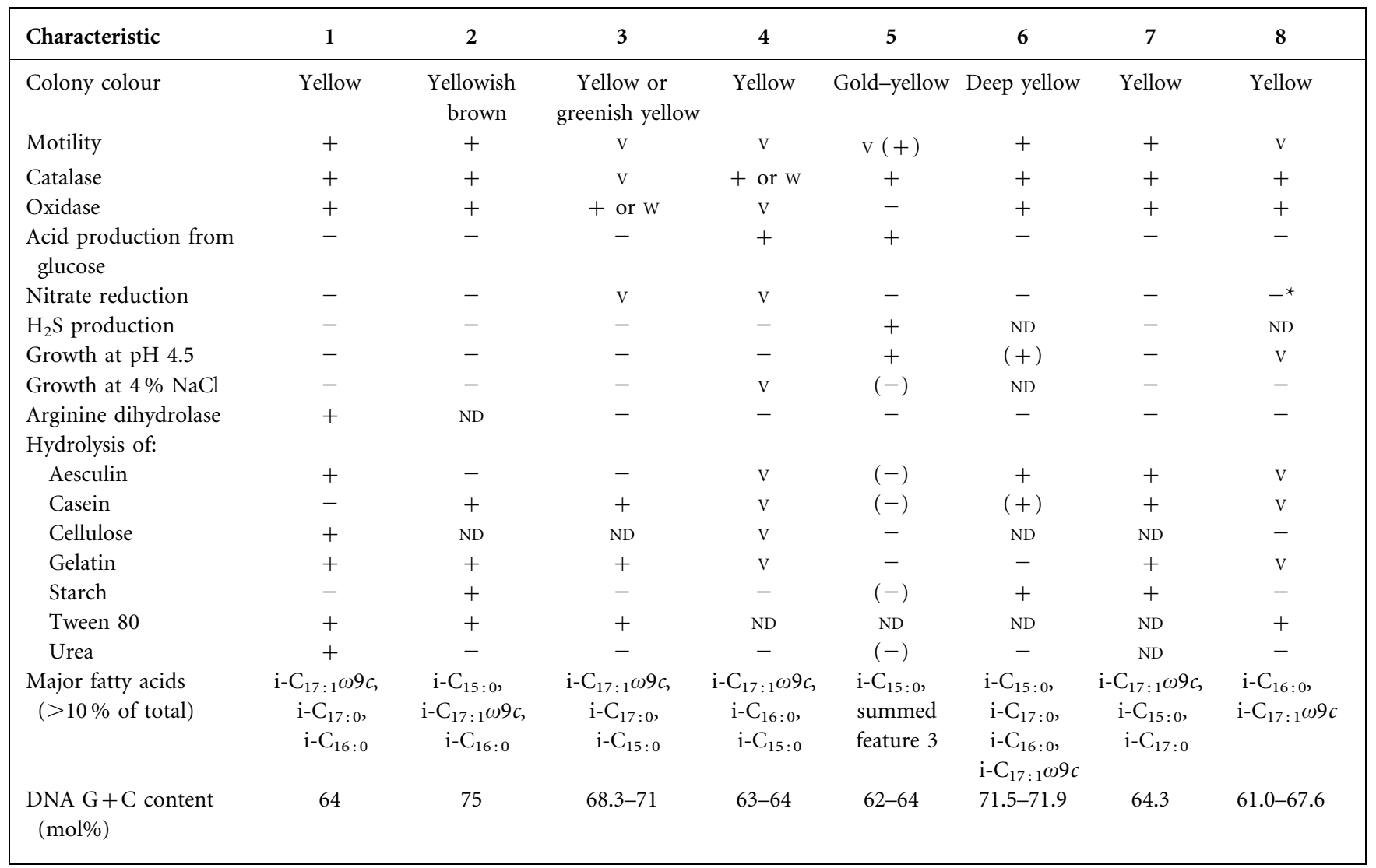

${ }^{\star}$ Positive for Rhodanobacter thiooxydans (Lee et al., 2007). 
(APLs) and phospholipids (PLs) (Supplementary Fig. S2a). Despite the similarities of the major components, strain KIS3-4 ${ }^{\mathrm{T}}$ could be distinguished from Dokdonella koreensis DSM $17203^{\mathrm{T}}$ (Supplementary Fig. S2b) by the presence of APL1, PL1 and PL2, and the absence of APL2, PL4 and an unidentified polar lipid. The predominant fatty acids $\left(>10 \%\right.$ of total fatty acids) of strain KIS3 $-4^{\mathrm{T}}$ were iso$\mathrm{C}_{17: 1} \omega 9 c \quad(32.8 \%)$, iso- $\mathrm{C}_{17: 0} \quad(18.0 \%)$ and iso- $\mathrm{C}_{16: 0}$ (12.7\%) (Supplementary Table S1). The major quinone in strain KIS3- $4^{\mathrm{T}}$ was ubiquinone $8(\mathrm{Q}-8)$, which is also found in all the members of the family Xanthomonadaceae. The $\mathrm{G}+\mathrm{C}$ content of the DNA was $64 \mathrm{~mol} \%$.

It is evident from the phylogenetic tree (Fig. 1) that strain KIS3 $-4^{\mathrm{T}}$ belongs to a distinct lineage in the family Xanthomonadaceae. The strain formed a monophyletic clade with the genera Aquimonas, Dokdonella, Dyella, Frateuria, Fulvimonas, Luteibacter and Rhodanobacter with $95 \%$ bootstrap support, which was confirmed by the maximum-parsimony tree. Strain KIS3-4 ${ }^{\mathrm{T}}$ revealed highest sequence similarities, with the exception of uncultured environmental clones (Costello \& Schmidt, 2006; Lozada et al., 2006), with Dyella species (93.1-93.7\%).

Strain KIS3 $-4^{\mathrm{T}}$ can be differentiated from closely related genera by the presence of arginine dihydrolase, the hydrolysis of cellulose and urea, the polar lipid pattern and the major fatty acid composition (Table 1, Supplementary Table S1 and Supplementary Fig. S2). Moreover, the similarity level $(<94 \%)$ of the $16 \mathrm{~S}$ rRNA gene sequence of strain KIS3-4 ${ }^{\mathrm{T}}$ with closely related genera within the family Xanthomonadaceae is much lower than $95 \%$, a value that has been proposed as a 'practicable border zone for genus definition' (Ludwig et al., 1998).

On the basis of these results, it is proposed that strain KIS3 $-4^{\mathrm{T}}$ represents a novel species in a new genus, Rudaea cellulosilytica gen. nov., sp. nov.

\section{Description of Rudaea gen. nov.}

Rudaea (Ru.da.e'a. N.L. fem. n. Rudaea an arbitrary name after RDA, Rural Development Administration, where taxonomic studies of this taxon were conducted).

Cells are Gram-negative, strictly aerobic, motile rods. Catalase- and oxidase-positive. Nitrate is not reduced. Glucose is not fermented. $\mathrm{H}_{2} \mathrm{~S}$ is not produced. Arginine dihydrolase is produced. The major isoprenoid quinone is ubiquinone- 8 . The major fatty acids $(>10 \%)$ are iso$\mathrm{C}_{17: 1} \omega 9 c$, iso- $\mathrm{C}_{17: 0}$ and iso- $\mathrm{C}_{16: 0}$. The DNA G $+\mathrm{C}$ content of the type strain of the type species is $64 \mathrm{~mol} \%$ (HPLC). Phylogenetically, the genus belongs to the family Xanthomonadaceae. The type species is Rudaea cellulosilytica.

\section{Description of Rudaea cellulosilytica sp. nov.}

Rudaea cellulosilytica (cel.lu.lo.si.ly'ti.ca. N.L. n. cellulosum cellulose; N.L. adj. lyticus dissolving; N.L. fem. adj. cellulosilytica cellulose-dissolving).

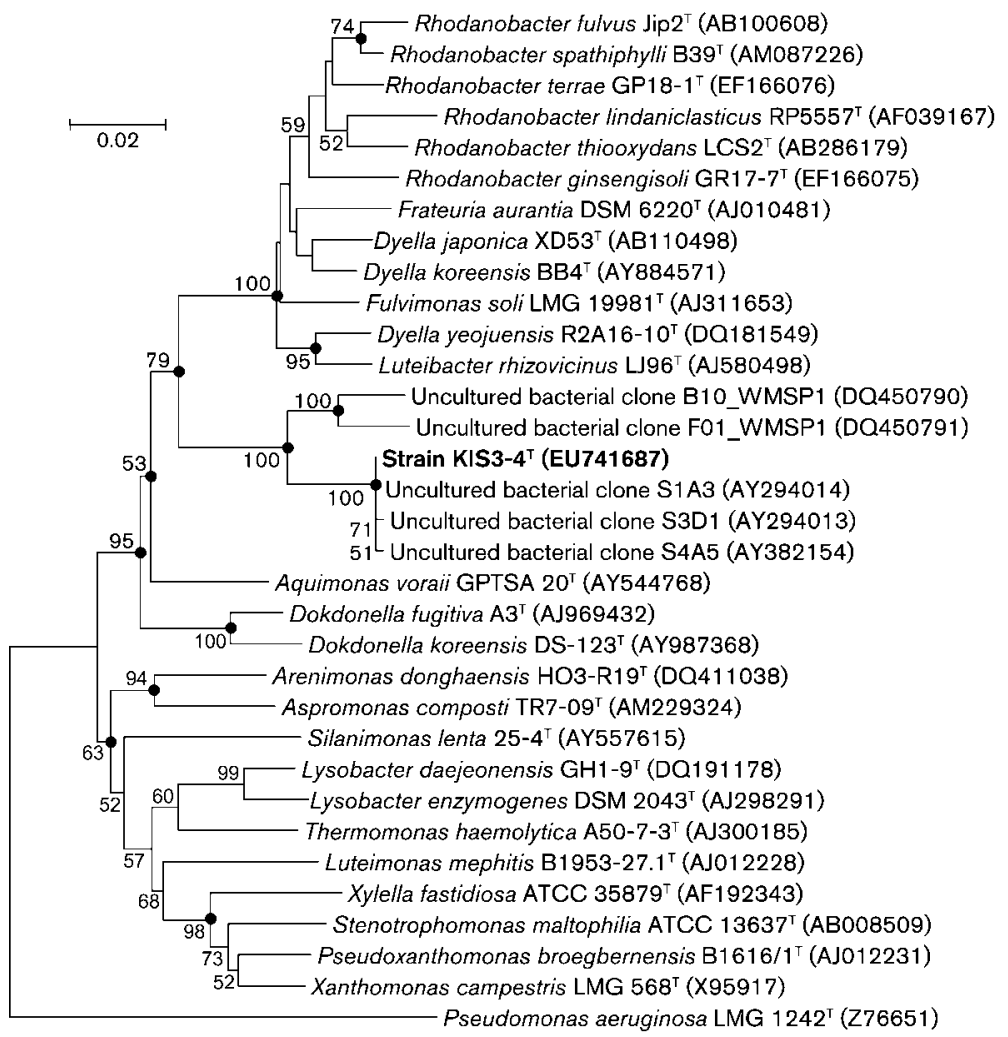

Fig. 1. Neighbour-joining tree based on partial 16S rRNA gene sequences showing the phylogenetic position of strain $\mathrm{KIS} 3-4^{\top}$. Bootstrap values $(>50 \%)$ based on 1000 resamplings are shown at branch nodes. Solid circles indicate that the corresponding branches were also recovered in the maximum-parsimony tree. The sequence of Pseudomonas aeruginosa LMG $1242^{\top}$ was used as the outgroup. Bar, 0.02 substitutions per nucleotide position. 
Displays the following properties in addition to those given in the genus description. Cells are $0.5 \mu \mathrm{m}$ wide and 1.0 $3.0 \mu \mathrm{m}$ long. Colonies are yellow, round or irregular on R2A medium. Growth occurs at $5-35{ }^{\circ} \mathrm{C}$ (optimum 28 $30{ }^{\circ} \mathrm{C}$ ), at pH $5-8$ (optimum pH $6-7$ ) and at $0-1 \% \mathrm{NaCl}$, but not at $2 \% \mathrm{NaCl}$. Hydrolyses CM-cellulose, Tween 80 and tyrosine, but not casein, chitin, DNA, hypoxanthine, starch or xanthine. Positive for urease, aesculin hydrolysis, gelatin hydrolysis and $\beta$-galactosidase, but negative for indole production and glucose fermentation (API 20NE). Assimilates D-glucose, D-mannose, $\mathrm{N}$-acetylglucosamine, maltose, inositol, sucrose, sodium acetate, lactic acid, salicin, melibiose, L-fucose, 3-hydroxybutyric acid and Lproline, but not L-arabinose, D-mannitol, potassium gluconate, capric acid, adipic acid, malic acid, trisodium citrate, phenylacetic acid, L-rhamnose, D-ribose, itaconic acid, suberic acid, sodium malonate, L-alanine, potassium 5-ketogluconate, glycogen, 3-hydroxybenzoic acid, L-serine, D-sorbitol, propionic acid, valeric acid, L-histidine, potassium 2-ketogluconate or 4-hydroxybenzoic acid (API 20NE and API ID 32GN strips). Acid is not produced from any substrates in the API 20E system. Produces alkaline phosphatase, esterase lipase (C8), leucine arylamidase, valine arylamidase, acid phosphatase, naphthol-AS-BIphosphohydrolase, $\alpha$-galactosidase, $\alpha$ - and $\beta$-glucosidase, $N$-acetyl- $\beta$-glucosaminidase and $\alpha$-mannosidase; weakly produces esterase (C4), cystine arylamidase, trypsin and $\alpha$-fucosidase; does not produce lipase (C14), $\alpha$-chymotrypsin or $\beta$-glucuronidase.

The type strain is $\mathrm{KIS} 3-4^{\mathrm{T}}\left(=\mathrm{KACC} 12734^{\mathrm{T}}=\mathrm{JCM}\right.$ $15422^{\mathrm{T}}$ ), isolated from soil from Daechung Island of the West Sea of Korea.

\section{Acknowledgements}

This work was supported by a grant (no. 20080401034028) from the BioGreen 21 Program, Rural Development Administration, Republic of Korea.

\section{References}

An, D.-S., Im, W.-T., Yang, H.-C., Yang, D.-C. \& Lee, S.-T. (2005). Dyella koreensis sp. nov., a $\beta$-glucosidase-producing bacterium. Int $J$ Syst Evol Microbiol 55, 1625-1628.

Breznak, J. A. \& Costilow, R. N. (1994). Physicochemical factors in growth. In Methods for General and Molecular Bacteriology, pp. 137-154. Edited by P. Gerhardt, R. G. E. Murray, W. A. Wood \& N. R. Krieg. Washington, DC: American Society for Microbiology.

Costello, E. K. \& Schmidt, S. K. (2006). Microbial diversity in alpine tundra wet meadow soil: novel Chloroflexi from a cold, watersaturated environment. Environ Microbiol 8, 1471-1486.

Cunha, S., Tiago, I., Pires, A. L., da Costa, M. S. \& Veríssimo, A. (2006). Dokdonella fugitiva sp. nov., a Gammaproteobacterium isolated from potting soil. Syst Appl Microbiol 29, 191-196.

De Clercq, D., Van Trappen, S., Cleenwerck, I., Ceustermans, A., Swings, J., Coosemans, J. \& Ryckeboer, J. (2006). Rhodanobacter spathiphylli sp. nov., a gammaproteobacterium isolated from the roots of Spathiphyllum plants grown in a compost-amended potting mix. Int J Syst Evol Microbiol 56, 1755-1759.

Groth, I., Schumann, P., Weiss, N., Martin, K. \& Rainey, F. A. (1996). Agrococcus jenensis gen. nov., sp. nov., a new genus of actinomycetes with diaminobutyric acid in the cell wall. Int J Syst Bacteriol 46, 234239.

Hiraishi, A. (1992). Direct automated sequencing of $16 \mathrm{~S}$ rDNA amplified by polymerase chain reaction from bacterial cultures without DNA purification. Lett Appl Microbiol 15, 210-213.

Im, W. T., Lee, S. T. \& Yokota, A. (2004). Rhodanobacter fulvus sp. nov., a $\beta$-galactosidase-producing gammaproteobacterium. J Gen Appl Microbiol 50, 143-147.

Jin, L., Kim, K. K., Im, W. T., Yang, H. C. \& Lee, S. T. (2007). Aspromonas composti gen. nov., sp. nov., a novel member of the family Xanthomonadaceae. Int J Syst Evol Microbiol 57, 1876-1880.

Johansen, J. E., Binnerup, S. J., Kroer, N. \& Mølbak, L. (2005). Luteibacter rhizovicinus gen. nov., sp. nov., a yellow-pigmented gammaproteobacterium isolated from the rhizosphere of barley (Hordeum vulgare L.). Int J Syst Evol Microbiol 55, 2285-2291.

Kim, B. Y., Weon, H. Y., Lee, K. H., Seok, S. J., Kwon, S. W., Go, S. J. \& Stackebrandt, E. (2006). Dyella yeojuensis sp. nov., isolated from greenhouse soil in Korea. Int J Syst Evol Microbiol 56, 2079-2082.

Kumar, S., Tamura, K. \& Nei, M. (2004). MEGA3: integrated software for molecular evolutionary genetics analysis and sequence alignment. Brief Bioinform 5, 150-163.

Kwon, S. W., Kim, J. S., Park, I. C., Yoon, S. H., Park, D. H., Lim, C. K. \& Go, S. J. (2003). Pseudomonas koreensis sp. nov., Pseudomonas umsongensis sp. nov. and Pseudomonas jinjuensis sp. nov., novel species from farm soils in Korea. Int J Syst Evol Microbiol 53, 21-27.

Lee, E. M., Jeon, C. O., Choi, I., Chang, K. S. \& Kim, C. J. (2005). Silanimonas lenta gen. nov., sp. nov., a slightly thermophilic and alkaliphilic gammaproteobacterium isolated from a hot spring. Int $J$ Syst Evol Microbiol 55, 385-389.

Lee, C. S., Kim, K. K., Aslam, Z. \& Lee, S. T. (2007). Rhodanobacter thiooxydans sp. nov., isolated from a biofilm on sulfur particles used in an autotrophic denitrification process. Int J Syst Evol Microbiol 57, 1775-1779.

Lozada, M., Figuerola, E. L. M., Itria, R. F. \& Erijman, L. (2006). Replicability of dominant bacterial populations after long-term surfactant-enrichment in lab-scale activated sludge. Environ Microbiol 8, 625-638.

Ludwig, W., Strunk, O., Klugbauer, S., Klugbauer, N., Weizenegger, M., Neumaier, J., Bachleitner, M. \& Schleifer, K. H. (1998). Bacterial phylogeny based on comparative sequence analysis. Electrophoresis 19, 554-568.

Mergaert, J., Cnockaert, M. C. \& Swings, J. (2002). Fulvimonas soli gen. nov., sp. nov., a $\gamma$-proteobacterium isolated from soil after enrichment on acetylated starch plastic. Int J Syst Evol Microbiol 52, 1285-1289.

Mesbah, M., Premachandran, U. \& Whitman, W. B. (1989). Precise measurement of the $\mathrm{G}+\mathrm{C}$ content of deoxyribonucleic acid by highperformance liquid chromatography. Int J Syst Bacteriol 39, 159-167.

Minnikin, D. E., O'Donnell, A. G., Goodfellow, M., Alderson, G., Athalye, M., Schaal, A. \& Parlett, J. H. (1984). An integrated procedure for the extraction of bacterial isoprenoid quinones and polar lipids. J Microbiol Methods 2, 233-241.

Nalin, R., Simonet, P., Vogel, T. M. \& Normand, P. (1999). Rhodanobacter lindaniclasticus gen. nov., sp. nov., a lindane-degrading bacterium. Int J Syst Bacteriol 49, 19-23.

Reasoner, D. J. \& Geldreich, E. E. (1985). A new medium for the enumeration and subculture of bacteria from potable water. Appl Environ Microbiol 49, 1-7. 
Saddler, G. S. \& Bradbury, J. F. (2005). Order III. Xanthomonadales. In Bergey's Manual of Systematic Bacteriology, 2nd edn, vol. 2, part B, pp. 63-122. Edited by D. J. Brenner, N. R. Krieg, J. T. Staley \& G. M. Garrity. New York: Springer.

Saha, P., Krishnamurthi, S., Mayilraj, S., Prasad, G. S., Bora, T. C. \& Chakrabarti, T. (2005). Aquimonas voraii gen. nov., sp. nov., a novel gammaproteobacterium isolated from a warm spring of Assam, India. Int J Syst Evol Microbiol 55, 1491-1495.

Smibert, R. M. \& Krieg, N. R. (1994). Phenotypic characterization. In Methods for General and Molecular Bacteriology, pp. 607-654. Edited by P. Gerhardt, R. G. E. Murray, W. A. Wood \& N. R. Krieg. Washington, DC: American Society for Microbiology.
Thompson, J. D., Higgins, D. G. \& Gibson, T. J. (1994). CLUSTAL W: improving the sensitivity of progressive multiple sequence alignment through sequence weighting, position-specific gap penalties and weight matrix choice. Nucleic Acids Res 22, 4673-4680.

Weon, H. Y., Kim, B. Y., Hong, S. B., Jeon, Y. A., Kwon, S. W., Go, S. J. \& Koo, B. S. (2007). Rhodanobacter ginsengisoli sp. nov. and Rhodanobacter terrae sp. nov., isolated from soil cultivated with Korean ginseng. Int J Syst Evol Microbiol 57, 2810-2813.

Xie, C.-H. \& Yokota, A. (2005). Dyella japonica gen. nov., sp. nov., a $\gamma$ proteobacterium isolated from soil. Int J Syst Evol Microbiol 55, 753-756.

Yoon, J. H., Kang, S. J. \& Oh, T. K. (2006). Dokdonella koreensis gen. nov., sp. nov., isolated from soil. Int J Syst Evol Microbiol 56, 145-150. 